\title{
An extensive pattern of atypical neural speech-sound discrimination in newborns at risk of dyslexia
}

Thiede, Anja ${ }^{a,}{ }^{*}$, Virtala, Paula ${ }^{a}$, Ala-Kurikka, lina ${ }^{a}$, Partanen, Eino ${ }^{a, b}$, Huotilainen, Minna ${ }^{a, c}$, Mikkola, Kaija $^{d}$, Leppänen, Paavo H.T. ${ }^{e}$, \& Kujala, Teija ${ }^{a}$

${ }^{\text {a }}$ Cognitive Brain Research Unit, Department of Psychology and Logopedics, Faculty of Medicine, P.O. box 9, 00014 University of Helsinki, Helsinki, Finland

${ }^{b}$ Center of Functionally Integrative Neuroscience (CFIN), Department of Clinical Medicine, Aarhus

University Hospital, Nørrebrogade 44, 8000 Aarhus C, Denmark

${ }^{c}$ Department of Education, P.O. Box 9, 00014 University of Helsinki, Helsinki, Finland

${ }^{d}$ Children's Hospital \& Department of Pediatrics, P.O. Box 281, 00029 Helsinki University Hospital, Helsinki, Finland

e Department of Psychology, P.O.Box 35, 40014 University of Jyväskylä, Jyväskylä, Finland

* Corresponding author. Address: Cognitive Brain Research Unit, Faculty of Medicine, University of Helsinki, P.O. box 9, 00014 University of Helsinki, Finland. Tel.: +358466572167, E-mail: anja.thiede@ helsinki.fi

\section{Research Highlights}

- Familial dyslexia risk is associated with deficient speech-sound processing already at birth.

- Mismatch responses to speech-sound changes were absent, diminished or atypical in at-risk newborns.

- Speech-processing deficits at birth may serve as early neural markers of language disorders. 


\section{Abstract}

Objective: Developmental dyslexia is usually associated with deficient neural speech-sound processing. Identifying early signs of dyslexia among the at-risk population is paramount to develop interventions that can be applied before school age. Potential early markers of dyslexia may be detected by assessing neural speech processing deficiencies with the mismatch response (MMR).

Methods: As the first step of a large-scale longitudinal study, we recorded MMRs to a pseudoword and its variants (changes in vowel duration, sound frequency of syllables, and vowel identity) with electroencephalography (EEG) from 88 newborns either at high familial risk, i.e., with a moderately to severely dyslexic parent, or at no risk, i.e., no dyslexia in close relatives.

Results: Abnormal neural discrimination of all speech-sound variants was found in high-risk infants: their MMRs were absent or diminished, had a different morphology and hemispheric lateralization compared to controls.

Conclusions: The results suggest an extensive pattern of atypical neural speech-sound discrimination in highrisk newborns.

Significance: This weak neural basis for speech discrimination may contribute to impaired language development, potentially leading to future reading problems.

Keywords: newborn, dyslexia, mismatch response (MMR), event-related potential (ERP), auditory, speech sound 


\section{Conflict of Interest Statement}

None of the authors have potential conflicts of interest to be disclosed.

\section{Acknowledgements}

The authors would like to thank research nurses Tarja Ilkka and Svetlana Permi for conducting the majority of the EEG recordings, all research assistants involved in this project for their help, and Prof. Laurel Trainor and Tommi Makkonen, M.Sc. (Tech.), for guidance and assistance during data analysis. Finally, we would like to thank all participating families for their motivation and engagement in this longitudinal study. This work was supported by Jane and Aatos Erkko Foundation and the Academy of Finland [project number 276414]. The funding sources were not involved in the planning and execution of the study, nor in the writing of the article and decision to submit. 


\section{Introduction}

Difficulties in learning to read and write can lead to severe problems in social and academic development. Developmental dyslexia, a learning impairment specific to reading and writing, affects $4-17 \%$ of the population (Elliott and Grigorenko 2014) despite affected individuals' otherwise intact cognitive abilities. The underlying cause for dyslexia is partially genetic, i.e., the genetic variation accounts for at least $50 \%$ (DeFries and Fulker 1985) or even up to $70-80 \%$ (Kere 2014) of the variation in reading and related difficulties in dyslexic individuals. Several dyslexia susceptibility genes have already been identified (Kere 2014).

Dyslexia can be diagnosed at school age, when children start to exhibit difficulties in redingskill acquisition. As difficulties in reading greatly hinder academic success, it is vital to find means to ameliorate reading deficiencies. If children at high risk of dyslexia could be identified and treated prior to school onset, social and academic outcomes of these children could be drastically improved (Gabrieli 2009). A prerequisite for designing early interventions is to identify reliable markers of the deficient neural processes that may underlie dyslexia.

One of the current leading theories on dyslexia suggests that the majority of affected individuals have a phonological processing impairment which was proposed to be based on a deficient formation, storage and/or retrieval of speech-sound representations in the brain (Ramus 2001; Ramus and Szenkovits 2008). As learning to read requires fast and accurate mapping of letters to their corresponding speech sounds in the brain, abnormal development of the speech-sound representations, or access to them, would result in inaccurate or slow assembly/access of the neural network required for fluent reading (Ramus and Szenkovits 2008). The fundamental deficiency in the development of speech-sound representations reflected in neurophysiological responses could serve as a neural predictor for future reading problems in dyslexia (Kujala 2007).

\subsection{Neurophysiological means to evaluate speech-sound processing during early development}

Speech-sound representations can be probed at the neural level with the mismatch negativity (MMN; Näätänen et al. 2007), an event-related potential (ERP) component elicited by rare deviants presented among 
frequent standard stimuli, hence reflecting sound discrimination in the brain. The MMN in adults is typically a negative deflection 150-250 ms after change onset and distributed fronto-centrally on the scalp (Näätänen 2001). It has been proposed that the $M M N$ is elicited when an incoming sound violates the expectation formed on the basis of previous sounds (Garrido et al. 2009). The response amplitude is greater to large than small sound changes and correlates with behavioral change detection performance, thus reflecting stimulus discrimination accuracy (Kujala and Näätänen 2010). However, the MMN also reflects activation of long-term memory traces in the human brain (Winkler et al. 1996). Its amplitude is larger to native than non-native speech-sound contrasts, indicating the influence of individual exposure and experience on the formation of MMN (Näätänen et al. 1997). Consequently, the MMN has been widely used to study speech-sound processing in healthy populations and in individuals with neurocognitive deficits (Näätänen et al. 2011). In developmental dyslexia, diminished MMN amplitudes have been found to speech- and non-speech-sound changes (Kujala and Näätänen 2001; Kujala 2007; Hämäläinen et al. 2013), suggesting an impairment of neural sound discrimination in dyslexia, consistent with the phonological deficit hypothesis.

Being elicited even in inattentive participants (Winkler 2007), MMN is a feasible tool to investigate auditory processing in early infancy. MMN has been recorded as early as at birth (Alho et al. 1990), and even prior to it (Huotilainen et al. 2005). However, the infant equivalent of MMN may differ drastically from the typical adult waveform and is therefore often referred to as mismatch response (MMR), a term also used hereafter. Compared to the adult MMN, the infant MMR is often positive in polarity (Trainor 2012) which has been suggested to arise from various factors (Kushnerenko et al. 2013). For example, positive MMRs could indicate neural immaturity and negative MMRs maturity (e.g., Mueller, Friederici, \& Mannel, 2012; cf. see also Leppänen et al., 2004). This view is supported by, e.g., positive MMRs being most pronounced in young infants and getting weaker with age (Morr et al. 2002; He et al. 2007, 2009) as well as negative MMRs being least pronounced in young infants and getting stronger with age during the first year of life (Kushnerenko et al. 2002; Trainor et al. 2003; He et al. 2007, 2009). Infant MMRs of opposite polarities might reflect distinct neural processes, as they can be separated by using different filter settings (Trainor et al. 2003; He et al. 2007) and as they differ in their scalp distribution (He et al. 2007). Positive and negative 
MMRs can also co-occur and overlap in time (Leppänen et al. 1997). Even though the exact mechanism of infant MMR generation remains unclear, regardless of response polarity, infant MMRs were suggested to be indices of auditory discrimination (Leppänen et al. 1997; Trainor et al. 2003).

Infant MMR studies have shed light on the development of early auditory abilities. For example, they have shown that already at birth, infants can discriminate basic auditory features, such as duration and frequency differences (Alho et al. 1990; Leppänen et al. 1997; Čeponiene et al. 2002). Newborns are even able to process complex sound relationships, like rules in sound patterns and musical chords (e.g., Virtala et al. 2013; Háden et al. 2015). Along with these abilities, newborns possess necessary prerequisites for language processing and, indeed, they can also neurally differentiate changes in language-relevant stimuli. For example, changes in vowels, consonants, and their durations in syllables or pseudowords elicit an MMR in newborns (Cheour-Luhtanen et al. 1995; Leppänen et al. 1999; Kushnerenko et al. 2001; Partanen et al. 2013).

\subsection{Speech-sound processing in infants at familial risk of dyslexia}

Familial risk of dyslexia can influence the elicitation of MMRs to speech-sound changes in early development. Six-month olds at risk of dyslexia were found to have smaller MMRs in the left hemisphere to consonant duration changes in a pseudoword than control infants at no risk of dyslexia (Leppänen et al. 2002). Twomonth old infants at risk of dyslexia exhibited diminished positive MMRs and absent late negative MMRs compared to control infants to changes in consonant-vowel-consonant (CVC) stimuli (van Leeuwen et al. 2008). In newborns at risk of dyslexia, ERPs were larger to shorter vowels in syllables, presented as deviant stimuli among syllables with long vowels, than in control newborns (Leppänen et al. 1999). This rather unexpected finding might result from differences in the obligatory responses (MMRs obtained from deviantstandard subtraction waves were not reported).

Importantly, longitudinal studies have shown that the presence or absence of certain auditory brain responses in early infancy is associated with future reading fluency (Van Zuijen et al. 2013; Schaadt et al. 2015). For example, later non-fluent readers were shown to have absent MMRs to consonant changes in 
a syllable in early infancy (Van Zuijen et al. 2013; Schaadt et al. 2015). However, for example, Leppänen et al. (2010) found no association between the absence of MMR to frequency changes in infants at risk of dyslexia and their later reading skills. Possibly, neural speech-sound discrimination is more strongly associated with dyslexia than non-speech-sound processing, in line with the phonological processing deficit model.

Besides differences in MMR amplitude, also hemispheric lateralization of the MMR was found to differ between infants at and not at dyslexia risk. For example, infants at risk of dyslexia exhibited larger positive amplitudes at the right hemisphere to changes in synthetic or CVC syllables than infants at no risk (Guttorm et al. 2001; van Leeuwen et al. 2008). Larger right-hemispheric positive MMRs were also found in at-risk newborns to syllable duration changes, whereas in control infants the responses were stronger at the left hemisphere (Pihko et al. 1999). However, the opposite lateralization pattern was found in at-risk newborns with later reading difficulties (left-lateralized) compared to control newborns who became fluent readers (right-lateralized) in ERPs to tone frequency changes (Leppänen et al. 2010). Taken together, infants at risk of dyslexia have atypical MMR lateralization patterns, but the results are not consistent.

Evidently, infants at risk of dyslexia have abnormal MMR amplitudes and lateralization from birth onwards. However, the interpretation of the prior results is often compromised by small, uneven, and/or unmatched sample sizes as well as different stimuli and change types being presented in different studies (Leppänen et al. 1999; Van Zuijen et al. 2013). Small sample sizes are particularly problematic in infant studies, as infant ERPs exhibit a large variance within and across individuals. Furthermore, as only a part of infants at familial risk of dyslexia will develop the disorder (Fisher and DeFries 2002), and as only a subgroup of them demonstrates extensive auditory processing deficits (Hämäläinen et al. 2013), large sample sizes are essential to detect signs of auditory dysfunctions.

Since brain responses in infancy were found to be associated with later language development and reading skills in pre-school and school age (e.g., Molfese 2000; Guttorm et al. 2005; Leppänen et al. 2010, 2012; Schaadt et al. 2015; Lohvansuu et al. 2018) and even earlier (Benasich et al. 2006; Cantiani et al. 2016), it is vital to determine how they deviate in those at dyslexia risk from the typical pattern. 


\subsection{Aims and hypotheses of the current study}

We aimed to investigate the nature of impaired speech-sound discrimination in a large sample of newborn infants at high familial risk of dyslexia based on a parental diagnosis of moderate to severe dyslexia, using a more extensive stimulus set than previous studies. As the first part of a longitudinal study (the DyslexiaBaby study, see Virtala \& Partanen, accepted), we recorded ERPs to pseudowords and MMRs to vowel duration, sound frequency of syllables, and vowel identity changes embedded in pseudowords. These deviances were chosen since the accurate detection of these features is essential in order to perceive speech sounds and word boundaries. First, we hypothesized that the ERP to the pseudoword could be diminished in at-risk infants. Second, we expected to find diminished or absent MMRs in these infants. Third, with an additional control paradigm, in which the long duration deviant was repeated alone (Schröger and Wolff 1998), we tested whether the MMRs obtained to duration changes reflect genuine duration change detection or whether the acoustic stimulus duration differences affect the MMRs (Kushnerenko et al. 2001). Fourth, based on previous studies, both the MMRs and the ERPs to standard stimuli were expected to exhibit an atypical lateralization in high-risk infants. 


\section{Methods}

\subsection{Participants}

The recruitment and participant selection process for this study is illustrated in Figure 1. Families were recruited via traditional and social media, maternity clinics and wards, and via the website of the DyslexiaBaby study. Two hundred and eight healthy full-term (gestational age at least 37 weeks, birth weight at least $2500 \mathrm{~g}$ ) Finnish newborns with normal hearing, having passed the routine screening in the hospital (Evoked Oto-Acoustic Emissions, EOAE), participated in the longitudinal study.

In order to be included in the at-risk group, one or both of the infant's biological parents had to have developmental dyslexia, confirmed by a recent diagnostic statement from a health care professional or dyslexia testing in the present study, in addition to a report of reading- and writing-related difficulties in childhood. Dyslexia testing consisted of questionnaires, interviews, and a Finnish standardized test measuring oral text, word, and pseudoword reading, as well as writing speed (Nevala et al. 2006). For the atrisk group, exclusion reasons were an individualized curriculum in elementary school of the dyslexic parent (potentially indicative of broader cognitive deficits), brain trauma of the dyslexic parent in childhood (possible non-heritable cause of dyslexic symptoms of the parent), and suspected or confirmed attention deficits in one or both parents (comorbid with dyslexia and may affect auditory ERPs, see, e.g., Yang et al. 2015). The present study reports a sub-sample of high-risk infants, selected according to test results of the parents, in which for at least one parent moderate to severe dyslexia had to be confirmed by a below-norm performance of at least 2 standard deviations $(S D)$ in reading or writing speed or accuracy in two or more of the subtests.

In order to be included in the control group, both of the infant's biological parents (or one when the other parent was not involved) had to report neither suspected nor diagnosed dyslexia nor other language- or learning-related disorders. Infants, whose epoched electroencephalography (EEG) data resulted in less than 50 accepted epochs for at least two deviant types were excluded (Figure 1).

The final sample included 44 newborns at high risk of dyslexia (high-risk group), and 44 at no risk of dyslexia (control group; Table 1, Figure 1). The groups did not differ in gender, gestational and 
measurement age, mothers' and fathers' educational background, or birth height and weight at a significance level of $5 \%$ (Table 1).

The Ethics Committee for Gynaecology and Obstetrics, Pediatrics and Psychiatry of the Hospital District of Helsinki and Uusimaa approved the study protocol and the study was performed in compliance with the Declaration of Helsinki. One or both parents of the newborn participants gave written informed consent to participate in the study prior to the experiment.

\subsection{Stimuli and Recordings}

A bi-syllabic Finnish pseudoword /tata/ and its variants were used as auditory stimuli. It was uttered by a female native Finnish speaker (first used by Pakarinen et al. 2014), with the stress on the first syllable and a natural ending. The total duration of the stimulus was $300 \mathrm{~ms}$, of which $\approx 251 \mathrm{~ms}$ were audible. The second syllable onset was at $\approx 168 \mathrm{~ms}$, and the onset of the second /a/ at $\approx 181 \mathrm{~ms}$ (Figure 2 ).

In the auditory variants (Table 2), the change occurred in the second syllable, in syllable frequency (/ta-ta/), vowel duration (/ta-ta:/), or vowel identity (/ta-to/). Variants were constructed by editing the /tata/ sound file (Adobe Audition CS6, 5.0, Build 708 and Praat 5.4.01). In all variants, the sound intensity level was root-mean-square (RMS) normalized to match the average intensity level of the /tata/ stimulus. Human (e.g., sigh, cry, laugh) and non-human (e.g., telephone ring, electric drill) novel sounds (duration $200 \mathrm{~ms}$ ) were presented very rarely among the standard and deviant stimuli. Responses recorded to these stimuli will be reported elsewhere.

The sounds were presented in a mixed multi-feature-oddball paradigm (Figure 3 ) in at least four $\approx 7$-min-long stimulus blocks. More data were recorded when the infant stayed calm. The pseudoword /tata/ was presented as the standard stimulus (probability on average $70.1 \%$ ), its variants with a duration, frequency, or vowel identity change were occasionally presented as rare deviants (on average $25.3 \%$, each individual deviant $\approx 8.5 \%$ ), and the novel sounds were presented very rarely (on average $4.5 \%$ ). One block contained 472 stimuli in total. Each deviant was presented at least 160 times and not more than 320 times during the experiment. The stimuli were presented with a varying stimulus-onset asynchrony (SOA) of 
$900 \pm 50 \mathrm{~ms}$ (randomly alternating between $850,860,870, \ldots, 940,950 \mathrm{~ms}$ ) in order to reduce expectancy effects related to the predictability of the stimulus onset, and to minimize an accumulation of non-phaselocked external periodic signals, such as line noise, in the ERP average. The order of the stimuli was pseudorandomized so that two deviants and novels were never presented in a row (i.e., a deviant or novel sound was always followed by a standard). The blocks started with four standard stimuli in a row. An additional block containing a control paradigm with 200 repetitions of the vowel duration deviant only ( $\approx 3$ min with the same varying SOA) was presented last, i.e., after four blocks, to obtain a controlled deviantminus-standard difference for the duration deviant. The total experiment duration was approximately one hour.

EEG recordings (sampling rate: $500 \mathrm{~Hz}$, low-pass filter: $100 \mathrm{~Hz}$ ) were carried out at Jorvi Hospital of Helsinki University Hospital in Espoo, and at a laboratory of the University of Jyväskylä, both in Finland. EEG was recorded with 18 active electrodes (headcap: ActiCap; amplifier: BrainProducts QuickAmp 10.08.14; software: BrainVision Recorder 1.20.0801; all: Brain Products GmbH, Gilching, Germany) placed according to the international $10 / 20$ system (Fp1/2, F7/8, F3/4, Fz, C3/4, Cz, P7/8, P3/4, Pz, Oz, LM, RM). The data were referenced online to the average of all electrodes.

During the recording, newborns were lying on their back in a crib and the auditory stimuli were presented with Presentation 17.2 Software (Neurobehavioural Systems Ltd., Berkeley, CA, USA) via a Genelec speaker placed approximately $40 \mathrm{~cm}$ from the newborn's head. The stimulus intensity was $\approx 65 \mathrm{~dB}$ at the infant's head (sound pressure level, SPL), the background noise of the room being $\approx 40 \mathrm{~dB}(\mathrm{SPL}$ ). The recording was conducted by a trained nurse or research assistant in a quiet hospital room (at Jorvi Hospital) or soundproof laboratory (at University of Jyväskylä). The state of the infant was classified with button presses on a response box (Cedrus RB844, Cedrus Corporation, California, USA) as 'active sleep', 'quiet sleep', 'awake', or 'intermediate sleep stage'. Infants of both groups spent equal relative amounts of time in active sleep (41\% in control, $40 \%$ in high-risk group), quiet sleep (16\% in control, $21 \%$ in high-risk group) and awake (19\% in control, $15 \%$ in high-risk group) states. 


\subsection{Data analysis}

The EEG data were pre-processed with MATLAB Release 2015a and 2017a (The MathWorks, Inc., Natick, Massachusetts, USA) as well as MATLAB toolboxes EEGlab 13.5.4b (Delorme and Makeig 2004) and CBRUPlugin2.0b (Tommi Makkonen, Cognitive Brain Research Unit, University of Helsinki). First, data were inspected visually, and channels with continuous noise (e.g., due to poor scalp contact) were excluded from further analysis. Then, the data were filtered offline using a Hamming-windowed sinc finite impulse response filter between 0.5 (high-pass, $0.25 \mathrm{~Hz}$ cutoff frequency) and $25 \mathrm{~Hz}$ (low-pass, $28.125 \mathrm{~Hz}$ cutoff frequency). Thereafter, stimulus blocks with visually identified excessive movement artifacts were excluded from the analysis, and data of other blocks, except for the duration control block, were combined. Finally, the data were segmented into $-100-840$ ms epochs around stimulus onset separately for each stimulus, channel, and participant. The epochs of those standard stimuli that were immediately following a deviant were excluded from the analysis. Baseline correction was applied $-100-0 \mathrm{~ms}$ prior to stimulus onset. The epochs with an amplitude exceeding $\pm 120 \mu \mathrm{V}$ in electrodes close to the eyes (Fp1, Fp2) were excluded to reduce eyemovement related artefacts. For all electrodes, epochs with amplitudes exceeding $\pm 3 S D$ from the mean of the individual participant's average for each stimulus type and epochs with a drift of more than $80 \mu \mathrm{V}$ from the start to the end of the epoch were rejected. The mean number of accepted epochs did not differ between groups (Table 3). As the final step of pre-processing, the data were re-referenced to the average of four electrodes: both mastoids (LM, RM) and electrode locations close to the mastoids (P7, P8) in order to display largest response amplitudes on fronto-central electrodes and to reduce the effects of often poor data quality on the mastoid electrodes. In 22 recordings, mastoids (20 cases, 8 in control, 12 in high-risk group) or P7/P8 ( 2 cases, 1 in control, 1 in high-risk group) had a poor signal, so that only mastoids or only P7 and P8 were used as references.

For the statistical analysis, six fronto-central electrodes were divided into four channel regions of interest (ROI): frontal, central, left, and right (Figure 4). In each ROI, the epoched data from the channels were averaged together in order to improve the signal-to-noise ratio, separately for each infant and stimulus type. Difference waves were obtained for all participants and each deviant by subtracting the standard- 
stimulus waveform from the deviant-stimulus waveform. Baselines were re-applied to $-100-0 \mathrm{~ms}$ prior to change onset instead of stimulus onset and therefore differed between the deviants: for duration deviant 125-225 ms (change onset at $225 \mathrm{~ms}$ ), and for frequency and vowel identity deviants $80-180 \mathrm{~ms}$ (change onset at $180 \mathrm{~ms}$ ). For the duration change, an additional 'controlled' duration difference wave was calculated by subtracting the ERP elicited in the duration control block from the duration change waveform obtained in other recording blocks.

Amplitudes of ERP components to the standard stimulus and MMR amplitudes to the three deviant types were analyzed. The latencies of interest were determined by visual inspection of grand average ERPs to standard stimuli and deviant-minus-standard subtraction waveforms to each deviant type. Maximal peaks of grand average ERPs for standard stimuli and difference waves for deviant types were identified and a 100-ms (when a response was visible in both groups) or 50-ms (when a response was visible only in one group and narrow) time window (TW) was chosen centered at this peak latency. For ERPs/MMRs with several peaks, the corresponding amount of TWs was selected, so that they covered ERPs/MMRs of both groups. This resulted in two TWs (TW 1, TW 2) to the standard stimulus, in three TWs (TW I, TW II, TW III) to duration and frequency changes, and in four TWs (TW I, TW II, TW III, TW IV) to vowel identity changes. The MMR to the duration control stimulus was calculated from one TW (TW III). TW I (referred to as early MMR responses from now on) represents activity that has its peak between 200 and $500 \mathrm{~ms}$ from stimulus onset. TW II represents activity that has its peak between 500 and $700 \mathrm{~ms}$, TW III between 700 and $800 \mathrm{~ms}$, and TW IV later than $800 \mathrm{~ms}$, all from stimulus onset (referred to as late MMR responses from now on).

To test whether the ERPs and MMRs were statistically significant, the mean ERP/MMR amplitudes in the chosen TWs were compared to zero using one-sample $t$-tests at the ROI with the maximal response amplitude. Effect sizes are reported as Cohen's $d$. Further statistical amplitude comparison was performed with repeated-measures ANOVAs in SPSS 24 (IBM, Armonk, New York, US). Group differences were assessed only if the ERP/MMR amplitude differed statistically significantly from zero (hereafter: was significant) in at least one group. Hemispheric differences and laterality $\mathrm{x}$ group interactions were investigated only if the ERP/MMR was significant in both groups. 
Group differences in both ERP components (TW 1, TW 2) of the standard response were tested separately by a $2 \times 2$ repeated-measures ANOVA with frontality $(F, C)$ as within-subjects factor and group (control, high-risk) as between-subjects factor. Hemispheric differences and laterality $\mathrm{x}$ group interaction effects were assessed with a similar, but separate ANOVA with laterality $(L, R)$ as within-subjects and group (control, high-risk) as between-subjects factor.

Group differences in MMR amplitudes were assessed with $2 \times 2$ repeated-measures ANOVAs separately for each deviant type (duration, duration control, frequency, vowel identity) and TW (I, II, III, IV) using frontality $(\mathrm{F}, \mathrm{C})$ as within-subjects factor and group (control, high-risk) as between-subjects factor. To investigate laterality effects and laterality $x$ group interactions, similar ANOVAs were used, in which frontality was replaced by laterality $(L, R)$ as within-subjects factor. Applicable corrections (Huynh-Feldt) were used when sphericity was violated (original degrees of freedom and corrected $F$ - and $p$-values are reported). In post-hoc comparisons, Bonferroni correction was applied, and only corrected $p$-values are reported. Effect sizes are reported as partial eta squared $\left(\eta_{p}{ }^{2}\right)$. 


\section{Results}

\subsection{ERPs to standard /tata/}

The pseudoword /tata/ evoked similar ERPs in both groups (Figure 5a). The distribution of the responses on the scalp is visualized in Figure $5 b$, while group, frontality and laterality effects in Figure $5 c$. A visual inspection of the waveform suggested that the pseudoword elicited two narrow early negative deflections that are most likely onset responses to the two syllables of the pseudoword, followed by a broad positivity-negativity complex (Figure 5a). The early positive component (233-333 ms, TW 1) was statistically significant (hereafter: significant) in both groups (Table 4 ) and did not significantly differ between groups in amplitude, $F(1,74)=$ 2.37, $p=.128, \eta_{p}{ }^{2}=.03$. The response was significantly larger at central compared to frontal channels (TW 1 , frontality main effect), $F(1,74)=23.79, p<.001, \eta_{p}^{2}=.24$, and significantly larger at the right than left hemisphere (TW 1, laterality main effect), $F(1,65)=19.19, p<.001, \eta_{p}{ }^{2}=.23$. A significant laterality $x$ group interaction effect, $F(1,65)=7.56, p=.008, \eta_{p}{ }^{2}=.10$, was found, and post-hoc tests indicated that the response was significantly larger at the right than left hemisphere in the control group only (left vs. right, mean difference $[M D]=-.823 \mu \mathrm{V}$, standard error of mean $[S E M]=.171 \mu \mathrm{V}, p<.001$ ). The late negative response (497-597 ms, TW 2) showed a trend for significance in the high-risk group only (Table 4, at central channels in high-risk group, $p=.077, d=-.27$ ), and thus, no further statistical analysis was pursued.

\subsection{MMRs to duration, frequency, and vowel identity changes}

MMRs to speech-sound changes in duration, frequency, and vowel identity are illustrated in Figure $6 a$ and the statistical test results regarding their significance are listed in Table 5 and Supplementary Table 1. Scalp maps are illustrated in Figure 6b. Duration changes elicited a significant negative MMR in the control group at 290-340 ms after stimulus onset (TW I), but no such response in the high-risk group. In addition, these changes elicited a significant positive MMR at 502-602 ms (TW II) and 677-777 ms (TW III) in both groups. Duration changes controlled for stimulus differences elicited a significant positive MMR at 641$741 \mathrm{~ms}$ (TW III) in both groups (Table 5, Figure 7, Supplementary Table 1). Frequency changes elicited no significant negative MMR in the high-risk group, but in the control group a significant negative response was 
found at 252-302 ms (TW I). A significant positive MMR to frequency changes was elicited at 578-678 ms (TW II) and 740-840 ms (TW III) in the high-risk group only. Vowel changes elicited a broad positive MMR, which in the high-risk group showed a trend for significance at 422-522 ms (TW I) and 536-636 ms (TW II) and was significant at 715-765 ms (TW III) and 790-840 ms (TW IV), and in the control group was significant at TWs I-IV.

Figure $6 c$ depicts statistical effects of both groups' MMRs to the three deviant types. The negative MMR (TW I) to duration changes was significantly smaller in high-risk than in control infants (group main effect), $F(1,74)=4.54, p=.036, \eta_{p}{ }^{2}=.06$. The positive MMR to duration changes (TW II) was significantly larger at frontal than central channels across groups (see scalp maps in Figure 6b; in TW II, frontality main effect), $F(1,74)=4.68, p=.034, \eta_{p}^{2}=.06$. For TW III, a trend for laterality $\times$ group interaction effect emerged, $F(1,65)=3.89, p=.053, \eta_{p}^{2}=.06$, and post-hoc tests showed that this effect was driven by significantly larger MMRs in the left than right hemisphere in the high-risk group only (left vs. right, $M D=.705 \mu \mathrm{V}, S E M=.291$ $\mu \mathrm{V}, p=.018)$

The negative MMR to frequency changes (TW I) tended to be smaller in the high-risk compared to control group (group main effect), $F(1,74)=3.36, p=.071, \eta_{p}{ }^{2}=.04$. The positive MMRs to the frequency changes exhibited significant laterality $\mathrm{x}$ group interaction effects in TW II, $F(1,65)=5.68, p=.020, \eta_{p}{ }^{2}=.08$, and TW III, $F(1,65)=5.60, p=.021, \eta_{p}^{2}=.08$. The high-risk group had significantly larger positive MMRs than the control group in the left hemisphere only (high-risk vs. control, TW II, MD = 1.463 $\mu \mathrm{V}, \mathrm{SEM}=.710$ ), $p=$ .043 , and TW III, MD $=1.857 \mu \mathrm{V}, \mathrm{SEM}=.786, p=.021)$. In addition, the high-risk group had significantly larger MMRs in the left than right hemisphere in TW II (left vs. right, $M D=.734 \mu \mathrm{V}, S E M=.364 \mu \mathrm{V}, p=.048$ ), wheareas the control group had the opposite pattern for TW III (left vs. right, $M D=-1.067 \mu \mathrm{V}, S E M=.450 \mu \mathrm{V}$, $p=.021)$.

A significant frontality $x$ group interaction was found for TW I to vowel identity changes, $F(1$, 74) $=4.26, p=.042, \eta_{p}^{2}=.05$. The interaction resulted from a trend of a smaller MMR in the high-risk compared to control group at frontal channels only (high-risk vs. control, $M D=-1.204 \mu \mathrm{V}, \mathrm{SEM}=.638 \mu \mathrm{V}, p$ $=.063$ ) and from a trend of a larger MMR at frontal compared to central channels in the control group (frontal 
vs. central, $M D=.548 \mu \mathrm{V}, \mathrm{SEM}=.291 \mu \mathrm{V}, p=.064)$. The MMR amplitudes in TW II tended to be smaller in the high-risk than control group (group main effect), $F(1,74)=3.18, p=.079, \eta_{p}{ }^{2}=.04$. For TW III, a significant laterality $\mathrm{x}$ group interaction, $F(1,65)=4.41, p=.040, \eta_{p}{ }^{2}=.06$, was found, driven by a trend for a smaller MMR in the high-risk than in the control group at the right hemisphere only (high-risk vs. control, $M D=$ $-1.283 \mu \mathrm{V}, \mathrm{SEM}=.662 \mu \mathrm{V}, p=.057)$, and by significantly smaller MMRs in the left compared to right hemisphere in the control group only (left vs. right, $M D=-.860 \mu \mathrm{V}, \operatorname{SEM}=.358 \mu \mathrm{V}, p=.019$ ). 


\section{Discussion}

This study aimed at determining the nature of deficits in neural encoding and discrimination of speech sounds in newborn infants at familial risk of dyslexia. To this end, ERPs to a repeated Finnish pseudoword/tata/ and MMRs to three types of changes embedded in it were recorded from newborns at high familial risk or no familial risk of dyslexia, and the response amplitudes and scalp distributions were compared between the groups. An early positive ERP component to the pseudoword was elicited at 233-333 ms in both groups, the response amplitudes not differing between the groups. However, the MMRs to speech-sound changes differed between the groups in several ways: Firstly, at early latencies negative MMRs to duration (at 290$340 \mathrm{~ms}$ ) and frequency changes (at 252-302 ms) were elicited in the control group, but were absent in the high-risk group. A group comparison of the early MMR amplitudes indicated smaller amplitudes to duration changes and a trend of smaller amplitudes to frequency changes in the high-risk than control group. Secondly, the high-risk group had late positive MMRs (at 578-678 ms and 740-840 ms) to frequency changes, which were absent in the control group. Thirdly, the positive MMR to vowel changes tended to have a smaller amplitude in the high-risk than the control group (at $422-522 \mathrm{~ms}$ and $536-636 \mathrm{~ms}$ ). Fourthly, the scalp distribution patterns differed between the groups: The positive MMRs were lateralized to the left hemisphere for duration and frequency changes in the high-risk group, whereas they were lateralized to the right hemisphere for frequency and vowel changes in the control group. Furthermore, the positive MMR to vowel changes tended to be more pronounced at frontal than central electrodes in the control group only, and tended to be smaller in the high-risk than in the control group at frontal electrodes. Taken together, these results suggest an extensive pattern of speech discrimination dysfunctions in newborns with a high familial risk of dyslexia.

\subsection{ERPs to standard pseudowords}

The repeating pseudoword elicited an early positive ERP response with a central- and right-preponderant scalp distribution in both groups. The standard ERP waveform consisted of two main components: an early positivity peaking at $283 \mathrm{~ms}$ and a wide late negativity peaking at $547 \mathrm{~ms}$ from stimulus onset, consistent 
with previous studies (Molfese 2000; Guttorm et al. 2001; Wunderlich et al. 2006). While the early positivity was significant in both groups with relatively large effect sizes, the negative response showed a trend of significance in the high-risk group only with small effect sizes. No group differences were found for the amplitudes or hemispheric distribution of the early positivity, which suggests that familial risk of dyslexia might not influence this early level of basic speech-sound encoding.

The distribution of the early positive ERP component in the present study was maximal over the right hemisphere at central channels in both groups. Hemispheric lateralization of speech processing in infants has varied between studies, with some suggesting an enhanced left-hemispheric lateralization (Molfese et al. 1975; Dehaene-Lambertz 2000), others suggesting right-hemispheric processing (Perani et al. 2011). Also ERPs to tones with different harmonics were found to be larger over the left than right hemisphere (Dehaene-Lambertz 2000), suggesting left-lateralized processing for non-speech sounds in infants. Our results with a right-hemispheric lateralization of the responses to the standard stimuli are in line with the functional magnetic resonance imaging (fMRI) study by Perani et al. (2011) in newborns. In our study, the large number of subjects ( 88 newborns) and the number of analysed EEG epochs for standard stimuli were large rendering a good signal-to-noise ratio (mean of 508 artifact-free EEG epochs). Therefore, the results can be considered reliable. However, they should be confirmed with a method yielding better source-localization accuracy. To summarize, the ERPs to pseudowords suggest that the cortical encoding of repetitive speech sounds might not be influenced by familial dyslexia risk at birth and, further, that speech processing or auditory processing in general might be differently lateralized at birth than later in development.

\subsection{Group differences in MMR amplitudes}

In contrast with the non-existent group differences for the ERPs to the standard stimulus, the MMRs to speech-sound deviants differed between the groups in several ways. We found early negative MMRs to duration and frequency changes in control infants that were absent in high-risk infants. Furthermore, the comparison of the early MMR amplitudes between the groups indicated significantly smaller amplitudes to 
duration changes and a trend of smaller amplitudes to frequency changes in the high-risk than control group. Late positive MMRs to frequency changes were only present in the high-risk group and absent in the control group. Vowel changes, in turn, elicited late positive MMRs in both groups which tended to be larger in controls. Previous studies demonstrating deficient auditory processing in newborns at risk of language impairments used non-speech sounds (Leppänen et al. 2010), speech sounds with one deviant type only (consonant duration, Leppänen et al. 1999), or involved older infants (Leppänen et al. 2002; Benasich et al. 2006; van Leeuwen et al. 2008; Van Zuijen et al. 2013; Schaadt et al. 2015). In our study, absent or diminished MMRs were found to all three deviant types presented in infants at high risk of dyslexia, suggesting several neural change detection abnormalities in high-risk infants already at birth.

In the present study, MMRs of both negative and positive polarity were elicited in newborns, consistent with some previous studies (Friederici et al. 2002; Háden et al. 2009; Virtala et al. 2013). Whereas duration, frequency, and vowel deviants demonstrated a positive MMR around 250-600 ms from stimulus onset in both groups (except for frequency change in the control group), it was preceded by a negative deflection at around 250-350 ms in response to the duration and frequency changes in the control group only. Co-existing negative and positive MMRs have been reported also previously in infants, as reviewed in the introduction. In the present study, the negative responses to the duration and frequency deviants peaked very early at around $90 \mathrm{~ms}$ and $100 \mathrm{~ms}$ from deviance onset, respectively. Similar early-latency negative responses to auditory deviants have been reported in infants also previously (Kushnerenko et al. 2007; Háden et al. 2009).

The emergence of an early negative component in the difference waveform has been interpreted as a sign of neural maturation (Trainor et al. 2003). The co-existence of fast negative MMRs and slow positive MMRs in the present results could thereby reflect a maturational stage where the negative MMR starts to appear, while the positive MMR gradually disappears. Alternatively, the positive MMR was suggested to develop towards the adult $\mathrm{P} 3 \mathrm{a}$, reflecting maturation of the auditory attention network (Kushnerenko et al. 2013). While the maturational pathways of the negative and positive MMRs and their underlying functions are still under debate, both components are thought to reflect aspects of an auditory 
change detection mechanism in infancy, essential for and likely indicative of future sensory-cognitive development. The present results demonstrated negative MMRs in the control group only, whereas MMRs in high-risk infants had a positive polarity. In light of the above-reviewed literature, the missing negative MMRs in the high-risk group and the missing positive MMR in the control group to the frequency change could be interpreted as signs of less mature auditory neural development in the high-risk infants. As the negative MMR had an earlier latency than the positive MMR, neural auditory change detection in the control group can also be interpreted as faster than in the high-risk group.

The absent early MMRs in the high-risk group to duration and frequency changes, and MMR amplitude differences between groups to duration, frequency, and vowel identity changes suggest that the auditory system of the control group can distinguish more accurately between the different speech-sound changes than that of the high-risk group, in line with with previous results showing diminished MMNs in dyslexic adults (Baldeweg et al. 1999; Kujala et al. 2003) and children (Maurer et al. 2003; Lovio et al. 2010). Also in young infants, similar evidence converges, as reviewed in the introduction.

The results of the aforementioned infant studies and our study demonstrate abnormal speechsound (phoneme) discrimination due to familial risk of dyslexia already in infancy. The ability to extract accurately speech-sound information and to discriminate speech sounds is important for typical language development involving the formation of neural representations of native language phonemes during the first year of life (Kuhl 2004). Consequently, abnormal phoneme discrimination at birth could lead to a weak or slow formation of native language phoneme representations. This is supported by studies showing that poorer neural speech processing in infancy as demonstrated by auditory ERPs predicts compromised language skills in childhood (Molfese 2000; Guttorm et al. 2005; Leppänen et al. 2010, 2012; Schaadt et al. 2015; Lohvansuu et al. 2018). Furthermore, the discrimination of, e.g., duration and frequency cues investigated in the present study is important for the detection of word boundaries (Friederici 2005). They have to be detected to differentiate between single phonemes and to segment words during the filtering process of the incoming continuous speech stream (Jusczyk 1999), which is relevant for language development. Problems in detecting word boundaries can therefore lead to further challenges in later 
language development. Overall, these poor foundations of speech processing, evident already at birth according to our results, can lead to difficulties in reading-skill acquisition (Goswami and Bryant 1990).

\subsection{Effects of the controlled duration paradigm}

The controlled duration paradigm was introduced to test whether the MMRs obtained reflect genuine duration discrimination instead of processing of the physical stimulus duration differences (Schröger and Wolff 1998). As our duration deviant lasted $100 \mathrm{~ms}$ longer than the /tata/ standard, these physical differences in the offsets of the standard and deviant stimuli could result in a deflection in the difference waveform that reflected processing of merely physical differences between the stimuli. The early negative MMR that was observed in the uncontrolled duration condition in infants at no risk was not seen in the controlled condition. It may be that this early negativity was elicited due to the physical features of the stimulus change, i.e., longer stimulus duration resulting in a different obligatory ERP response (Jacobsen and Schröger 2003). However, we found that a late positive MMR was still elicited in both groups when the stimulus differences were controlled for (i.e., when the duration deviant ERP was compared to the ERP to the same stimulus acting as a standard in the control condition). This supports and extends previous findings that the infant MMR reflects genuine change detection in the auditory system (Kushnerenko et al. 2002; Háden et al. 2016). Future studies should further investigate, what kind of sensory and cognitive functions these early negative and late positive MMRs reflect at birth.

\subsection{Group differences in the MMR scalp distribution}

The MMRs were distributed differently on the scalp between the two groups, both in front-back and lateral dimensions. This suggests altered neural generators in dyslexia consistent with previous studies in adults (e.g., Kujala et al. 2003; Renvall and Hari 2003).

Interactions between laterality and group were found to all speech-sound changes in the late positive $M M R$, indicating left-lateralized processing in the high-risk group (of duration and frequency changes), and right-lateralized processing in the control group (of frequency and vowel changes). The 
laterality findings of the present study are rather unexpected, since processing of speech in adults has been repeatedly suggested to be left-lateralized (e.g., Kimura 1967). Furthermore, in newborns, left-lateralized MMRs were found to syllable duration changes in a healthy control group and right-lateralized MMRs in a group at risk of dyslexia (Pihko et al. 1999). A similar lateralization pattern was shown in 2-month-old infants to CVC syllable changes (van Leeuwen et al. 2008). Yet, some findings on the lateralization of auditory change discrimination are consistent with ours. For example, control newborns that turned into fluent readers had right-lateralized ERPs to deviant tone frequencies and at-risk newborns with later reading problems exhibited left-lateralized ERPs to deviant stimuli (Leppänen et al. 2010). Moreover, a study with 2-month-old infants found that MMRs to CVC syllable changes were right-lateralized in control-group infants who later became fluent readers (Van Zuijen et al. 2013). The abnormal lateralization patterns in high-risk newborns in our study extend the dissenting literature on this topic in dyslexia-risk infants by showing a rather consistent MMR lateralization pattern in newborns to three speech-sound changes investigated in the same infants. Future research should aim to clarify whether lateralization is influenced by, for instance, the use of nonspeech vs. speech stimuli and the maturation of the auditory system.

The trend for diminished frontal positive MMRs to vowel changes in the high-risk infants as well as the trend for frontally pronounced positive MMRs to vowel changes in the control infants could suggest that the sources of positive MMR generators are atypically distributed in the anterior-posterior dimension in the high-risk infants. This very preliminary result might suggest a diminished frontal MMN generator in dyslexia, which would be compatibe with the functional and structural abnormalities in the frontal lobes observed in dyslexia (Eckert et al. 2003).

The observed differences in MMR scalp distributions between groups in this study could stem from different cortical locations or orientations of MMR generators in high-risk vs. no-risk infants. However, this and most of previous infant EEG studies were not designed to estimate MMR sources. Due to a small amount of electrodes recorded in this study, the above-discussed findings on scalp distributions should be confirmed by studies designed for better source localization, e.g., using high-density EEG, additional anatomical MRIs, or magnetoencephalography. 


\subsection{Summary and conclusions}

Our novel results shed light on the nature of speech processing deficits in newborns at high risk of dyslexia, showing an extensive pattern of abnormal speech-sound discrimination in high-risk newborns including absent or weaker MMRs, as well as atypical MMR polarities and lateralization patterns. These results, with larger group sizes and a more extensive stimulus set than in previous studies, support and extend previous findings. Abnormalities in the neural discrimination of speech at newborn age could result in weak, inaccurate, or slow formation of neural speech-sound representations in the brain, which can be a precursor for impaired language and reading-skill acquisition. The findings of this study can contribute to the early detection of infants at highest risk of dyslexia. Revealing the neural basis and nature of these speech processing deficits already at birth enables the design and implementation of means to support language development from the beginning of life. 


\section{References}

Alho K, Sainio K, Sajaniemi N, Reinikainen K, Näätänen R. Event-related brain potential of human newborns to pitch change of an acoustic stimulus. Electroencephalogr Clin Neurophysiol Potentials Sect. 1990 $\operatorname{Mar} ; 77(2): 151-5$

Baldeweg T, Richardson A, Watkins S, Foale C, Gruzelier J. Impaired auditory frequency discrimination in dyslexia detected with mismatch evoked potentials. Ann Neurol. 1999 Apr;45(4):495-503.

Benasich AA, Choudhury N, Friedman JT, Realpe-Bonilla T, Chojnowska C, Gou Z. The infant as a prelinguistic model for language learning impairments: Predicting from event-related potentials to behavior. Neuropsychologia. 2006;44(3):396-411.

Cantiani C, Riva V, Piazza C, Bettoni R, Molteni M, Choudhury N, et al. Auditory discrimination predicts linguistic outcome in Italian infants with and without familial risk for language learning impairment. Dev Cogn Neurosci. 2016 Aug;20:23-34.

Čeponiene R, Kushnerenko E, Fellman V, Renlund M, Suominen K, Näätänen R. Event-related potential features indexing central auditory discrimination by newborns. Cogn Brain Res. 2002 Feb;13(1):101-13.

Cheour-Luhtanen M, Alho K, Kujala T, Sainio K, Reinikainen K, Renlund M, et al. Mismatch negativity indicates vowel discrimination in newborns. Hear Res. 1995 Jan;82(1):53-8.

DeFries JC, Fulker DW. Multiple regression analysis of twin data. Behav Genet. 1985;15(5):467-73.

Dehaene-Lambertz G. Cerebral specialization for speech and non-speech stimuli in infants. J Cogn Neurosci. 2000 May;12(3):449-60.

Delorme A, Makeig S. EEGLAB: an open source toolbox for analysis of single-trial EEG dynamics including independent component analysis. J Neurosci Methods. 2004 Mar;134(1):9-21.

Eckert MA, Leonard CM, Richards TL, Aylward EH, Thomson J, Berninger VW. Anatomical correlates of dyslexia: Frontal and cerebellar findings. Brain. 2003;126(2):482-94.

Elliott JG, Grigorenko EL. The Dyslexia Debate. Cambridge University Press; 2014. (Cambridge Studies in Cognitive and Perceptual Development).

Fisher SE, Defries JC. Developmental dyslexia: Genetic dissection of a complex cognitive trait. Nat Rev 
Neurosci. 2002;3(10):767-80.

Friederici AD. Neurophysiological markers of early language acquisition: From syllables to sentences. Trends Cogn Sci. 2005;9(10):481-8.

Friederici AD, Friedrich $M$, Weber $C$. Neural manifestation of cognitive and precognitive mismatch detection in early infancy. Neuroreport. 2002;13(10):1251-4.

Gabrieli JDE. Dyslexia: A New Synergy Between Education and Cognitive Neuroscience. Science (80- ). 2009 Jul 17;325(5938):280-3.

Garrido MI, Kilner JM, Stephan KE, Friston KJ. The mismatch negativity: A review of underlying mechanisms. Clin Neurophysiol. 2009 Mar;120(3):453-63.

Goswami U, Bryant P. Phonological skills and learning to read. London: Lawrence Erlbaum Associates, Inc.; 1990.

Guttorm TK, Leppänen PHT, Poikkeus A-M, Eklund KM, Lyytinen P, Lyytinen H. Brain Event-Related Potentials (ERPs) Measured at Birth Predict Later Language Development in Children with and Without Familial Risk for Dyslexia. Cortex. 2005 Jan;41(3):291-303.

Guttorm TK, Leppänen PHT, Richardson U, Lyytinen H. Event-Related Potentials and Consonant Differentiation in Newborns with Familial Risk for Dyslexia. J Learn Disabil. 2001 Nov 18;34(6):534-44. Háden GP, Németh R, Török M, Winkler I. Predictive processing of pitch trends in newborn infants. Brain Res. 2015 Nov;1626:14-20.

Háden GP, Németh R, Török M, Winkler I. Mismatch response (MMR) in neonates: Beyond refractoriness. Biol Psychol. 2016 May;117:26-31.

Háden GP, Stefanics G, Vestergaard MD, Denham SL, Sziller I, Winkler I. Timbre-independent extraction of pitch in newborn infants. Psychophysiology. 2009;46(1):69-74.

Hämäläinen JA, Salminen HK, Leppänen PHT. Basic Auditory Processing Deficits in Dyslexia. J Learn Disabil. 2013 Sep 8;46(5):413-27.

He C, Hotson L, Trainor L. Mismatch Responses to Pitch Changes in Early Infancy. J Cogn Neurosci. 2007 May;19(5):878-92. 
He C, Hotson L, Trainor LJ. Development of infant mismatch responses to auditory pattern changes between 2 and 4 months old. Eur J Neurosci. 2009;29(4):861-7.

Huotilainen M, Kujala A, Hotakainen M, Parkkonen L, Taulu S, Simola J, et al. Short-term memory functions of the human fetus recorded with magnetoencephalography. Neuroreport. 2005 Jan 19;16(1):81-4.

Jacobsen T, Schröger E. Measuring duration mismatch negativity. Clin Neurophysiol. 2003;114(6):1133-43. Jusczyk PW. How infants beging to extact words from speech. Trends Cogn Sci. 1999;3(9):323-8.

Kere J. The molecular genetics and neurobiology of developmental dyslexia as model of a complex phenotype. Biochem Biophys Res Commun. 2014 Sep 19;452(2):236-43.

Kimura D. Functional Asymmetry of the Brain in Dichotic Listening. Cortex. 1967 Jun;3(2):163-78.

Kuhl PK. Early language acquisition: cracking the speech code. Nat Rev Neurosci. 2004 Nov;5(11):831-43.

Kujala T. The Role of Early Auditory Discrimination Deficits in Language Disorders. J Psychophysiol. 2007 Jan;21(3-4):239-50.

Kujala T, Belitz S, Tervaniemi M, Näätänen R. Auditory sensory memory disorder in dyslexic adults as indexed by the mismatch negativity. Eur J Neurosci. 2003 Mar;17(6):1323-7.

Kujala T, Näätänen R. The mismatch negativity in evaluating central auditory dysfunction in dyslexia. Neurosci Biobehav Rev. 2001 Aug;25(6):535-43.

Kujala T, Näätänen R. The adaptive brain: A neurophysiological perspective. Prog Neurobiol. 2010;91(1):5567.

Kushnerenko E, Ceponiene R, Balan P, Fellman V, Näätänen R. Maturation of the auditory change detection response in infants: a longitudinal ERP study. Neuroreport. 2002 Oct 28;13(15):1843-8.

Kushnerenko E, Cheour M, Ceponiene R, Fellman V, Renlund M, Soininen K, et al. Central Auditory Processing of Durational Changes in Complex Speech Patterns by Newborns: An Event-Related Brain Potential Study. Dev Neuropsychol. 2001 Feb;19(1):83-97.

Kushnerenko E V., Van den Bergh BRH, Winkler I. Separating acoustic deviance from novelty during the first year of life: a review of event-related potential evidence. Front Psychol. 2013;4:595.

Kushnerenko E, Winkler I, Horváth J, Näätänen R, Pavlov I, Fellman V, et al. Processing acoustic change and 
novelty in newborn infants. Eur J Neurosci. 2007 Jun 16;26(1):265-74.

van Leeuwen T, Been P, van Herten M, Zwarts F, Maassen B, van der Leij A. Two-month-old infants at risk for dyslexia do not discriminate /bAk/ from /dAk/: A brain-mapping study. J Neurolinguistics. 2008;21(4):333-48.

Leppänen PHT, Eklund KM, Lyytinen H. Event-related brain potentials to change in rapidly presented acoustic stimuli in newborns. Dev Neuropsychol. 1997 Jan;13(2):175-204.

Leppänen PHT, Guttorm TK, Pihko E, Takkinen S, Eklund KM, Lyytinen H. Maturational effects on newborn ERPs measured in the mismatch negativity paradigm. Exp Neurol. 2004 Nov;190(SUPPL. 1):91-101.

Leppänen PHT, Hämäläinen JA, Guttorm TK, Eklund KM, Salminen H, Tanskanen A, et al. Infant brain responses associated with reading-related skills before school and at school age. Clin Neurophysiol. 2012 Jan;42(1-2):35-41.

Leppänen PHT, Hämäläinen JA, Salminen HK, Eklund KM, Guttorm TK, Lohvansuu K, et al. Newborn brain event-related potentials revealing atypical processing of sound frequency and the subsequent association with later literacy skills in children with familial dyslexia. Cortex. 2010 Nov;46(10):1362-76. Leppänen PHT, Pihko E, Eklund KM, Lyytinen H. Cortical responses of infants with and without a genetic risk for dyslexia: II. Group effects. Neuroreport. 1999 Apr 6;10(5):969-73.

Leppänen PHT, Richardson U, Pihko E, Eklund KM, Guttorm TK, Aro M, et al. Brain responses to changes in speech sound durations differ between infants with and without familial risk for dyslexia. Dev Neuropsychol. $2002 \operatorname{Jan}$ 8;22(1):407-22.

Lohvansuu K, Hämäläinen JA, Ervast L, Lyytinen H, Leppänen PHT. Longitudinal interactions between brain and cognitive measures on reading development from 6 months to 14 years. Neuropsychologia. 2018;108(May 2017):6-12.

Lovio R, Näätänen R, Kujala T. Abnormal pattern of cortical speech feature discrimination in 6-year-old children at risk for dyslexia. Brain Res. 2010 Jun;1335:53-62.

Maurer U, Bucher K, Brem S, Brandeis D. Altered responses to tone and phoneme mismatch in kindergartners at familial dyslexia risk. Neuroreport. 2003;14(17):2245-50. 
Molfese DL. Predicting Dyslexia at 8 Years of Age Using Neonatal Brain Responses. Brain Lang. 2000 May;72(3):238-45.

Molfese DL, Freeman RB, Palermo DS. The ontogeny of brain lateralization for speech and nonspeech stimuli. Brain Lang. 1975 Jan;2(3):356-68.

Morr ML, Shafer VL, Kreuzer J a., Kurtzberg D. Maturation of mismatch negativity in typically developing infants and preschool children. Ear Hear. 2002 Apr;23(2):118-36.

Mueller JL, Friederici AD, Mannel C. Auditory perception at the root of language learning. Proc Natl Acad Sci. 2012;109(39):15953-8.

Näätänen R. The perception of speech sounds by the human brain as reflected by the mismatch negativity (MMN) and its magnetic equivalent (MMNm). Psychophysiology. 2001 Jan;38(1):1-21.

Näätänen R, Kujala T, Kreegipuu K, Carlson S, Escera C, Baldeweg T, et al. The mismatch negativity: an index of cognitive decline in neuropsychiatric and neurological diseases and in ageing. Brain. 2011 Dec 1;134(12):3435-53.

Näätänen R, Lehtokoski A, Lennes M, Cheour M, Huotilainen M, livonen A, et al. Language-specific phoneme representations revealed by electric and magnetic brain responses. Nature. 1997 Jan $30 ; 385(6615): 432-4$

Näätänen R, Paavilainen $P$, Rinne $T$, Alho $K$. The mismatch negativity (MMN) in basic research of central auditory processing: A review. Clin Neurophysiol. 2007 Dec;118(12):2544-90.

Nevala J, Kairaluoma L, Ahonen T, Aro M, Holopainen L. Lukemis- ja kirjoittamistaitojen yksilötestistö nuorille ja aikuisille. Jyväskylä: Niilo Mäki Instituutti; 2006.

Pakarinen S, Sokka L, Leinikka M, Henelius A, Korpela J, Huotilainen M. Fast determination of MMN and P3a responses to linguistically and emotionally relevant changes in pseudoword stimuli. Neurosci Lett. 2014;577:28-33.

Partanen E, Pakarinen S, Kujala T, Huotilainen M. Infants' brain responses for speech sound changes in fast multifeature MMN paradigm. Clin Neurophysiol. 2013 Aug;124(8):1578-85.

Perani D, Saccuman MC, Scifo P, Anwander A, Spada D, Baldoli C, et al. Neural language networks at birth. 
Proc Natl Acad Sci. 2011 Nov 8;108(45):18566-18566.

Pihko E, Leppänen PHT, Eklund KM, Cheour M, Guttorm TK, Lyytinen H. Cortical responses of infants with and without a genetic risk for dyslexia: I. Age effects. Neuroreport. 1999 Apr 6;10(5):901-5.

Ramus F. Dyslexia: Talk of two theories. Nature. 2001 Jul 26;412(6845):393-5.

Ramus F, Szenkovits G. What Phonological Deficit? Q J Exp Psychol. 2008 Jan 30;61(1):129-41.

Renvall H, Hari R. Diminished auditory mismatch fields in dyslexic adults. Ann Neurol. 2003;53(5):551-7.

Schaadt G, Männel C, van der Meer E, Pannekamp A, Oberecker R, Friederici AD. Present and past: Can writing abilities in school children be associated with their auditory discrimination capacities in infancy? Res Dev Disabil. 2015 Dec;47:318-33.

Schröger E, Wolff C. Behavioral and electrophysiological effects of task-irrelevant sound change: A new distraction paradigm. Cogn Brain Res. 1998;7(1):71-87.

Trainor L. Musical experience, plasticity, and maturation: Issues in measuring developmental change using EEG and MEG. Ann N Y Acad Sci. 2012 Apr;1252(1):25-36.

Trainor LJ, McFadden M, Hodgson L, Darragh L, Barlow J, Matsos L, et al. Changes in auditory cortex and the development of mismatch negativity between 2 and 6 months of age. Int J Psychophysiol. 2003;51(1):515.

Virtala P, Huotilainen M, Partanen E, Fellman V, Tervaniemi M. Newborn infants' auditory system is sensitive to Western music chord categories. Front Psychol. 2013 Jan;4:492.

Virtala P, Partanen E. Can very early music interventions promote at-risk infants' development? Ann N Y Acad Sci. in press.

Winkler I. Interpreting the Mismatch Negativity. J Psychophysiol. 2007 Jan;21(3-4):147-63.

Winkler I, Karmos G, Näätänen R. Adaptive modeling of the unattended acoustic environment reflected in the mismatch negativity event-related potential. Brain Res. 1996;742(1-2):239-52.

Wunderlich JL, Cone-Wesson BK, Shepherd R. Maturation of the cortical auditory evoked potential in infants and young children. Hear Res. 2006 Feb;212(1-2):185-202.

Yang M-T, Hsu C-H, Yeh P-W, Lee W-T, Liang J-S, Fu W-M, et al. Attention deficits revealed by passive auditory 
change detection for pure tones and lexical tones in ADHD children. Front Hum Neurosci. 2015 Aug 26;9(August):470.

Van Zuijen TL, Plakas A, Maassen BAM, Maurits NM, Van der Leij A. Infant ERPs separate children at risk of dyslexia who become good readers from those who become poor readers. Dev Sci. 2013;16(4):554-63. 


\section{Tables}

Table 1

Background Data (Mean, M, in Bold, and Standard Deviation, SD) of Newborn Participants and Independentsample t-statistics Including Degrees of Freedom (df) and Statistical Significance (p) for Group Differences.

\begin{tabular}{|c|c|c|c|c|c|c|c|}
\hline \multirow[b]{2}{*}{ Variable } & \multicolumn{2}{|c|}{ Control group } & \multicolumn{2}{|c|}{ High-risk group } & \multicolumn{3}{|c|}{ t-statistics } \\
\hline & $M$ & $S D$ & $M$ & $S D$ & $t$ & $d f$ & $p$ \\
\hline$N$ (males) & 44 & $(25)$ & 44 & $(25)$ & & & \\
\hline Gestational age [weeks] & 40.1 & 1.1 & 40.1 & 0.9 & 0.15 & 86 & .885 \\
\hline Age at measurement [days] & 8.9 & 5.1 & 9.1 & 4.0 & -0.26 & 86 & .798 \\
\hline Mother's education [years] & 17.6 & 2.6 & 17.0 & 2.2 & 1.06 & 83 & .293 \\
\hline Father's education [years] & 16.8 & 3.1 & 15.5 & 3.2 & 1.83 & 80 & .070 \\
\hline Birth weight [g] & 3558 & 545 & 3608 & 386 & -0.50 & 86 & .616 \\
\hline Birth height $[\mathrm{cm}]$ & 50.9 & 2.2 & 50.9 & 1.9 & 0.05 & 86 & .959 \\
\hline 5-min Apgar score (range) ${ }^{1}$ & $8-10$ & & $8-10$ & & & & \\
\hline
\end{tabular}

1 Two high-risk infants had missing Apgar values, but were considered healthy, as there were no reported complications at birth. One high-risk infant had missing EOAE values due to a broken measurement machine, but the consequent hearing test in the maternity clinic indicated normal hearing. Therefore, these three infants were included in the final sample. 
Table 2

Description of Auditory Variants.

\begin{tabular}{|c|c|c|}
\hline Deviant & Notation & Description of change \\
\hline Duration & /ta-ta:/ & $\begin{array}{l}\text { length of second syllable increased from } 71 \mathrm{~ms} \text { to } 158 \mathrm{~ms} \text { by copy and } \\
\text { paste of the /a/-phoneme; total length } 400 \mathrm{~ms} \text {, of which approximately } \\
327 \mathrm{~ms} \text { were audible }\end{array}$ \\
\hline Frequency & $/$ ta-ta/ & $\begin{array}{l}\text { increase of fundamental frequency (FO) level of second syllable from } \\
175 \mathrm{~Hz} \text { to } 225 \mathrm{~Hz} \text { (5 semitones higher) }\end{array}$ \\
\hline Vowel change & /ta-to/ & $\begin{array}{l}\text { replacement of second /ta/ syllable with /to/ syllable as part of } \\
\text { naturally uttered pseudoword /ta-to/ (Pakarinen et al. 2014); start time } \\
\text { and duration of second syllable matched to /tata/ stimulus; F0- } \\
\text { controlled to match F0-level of /tata/ stimulus }\end{array}$ \\
\hline
\end{tabular}


Table 3

Means (M, in Bold) and Standard Deviations (SD) of Accepted Epochs for Standard and Deviant Stimuli in Control and High-risk Groups and Independent-samples t-statistics Including Degrees of Freedom (df) and Significance Levels (p) for Differences of Accepted Epochs Between Groups.

\begin{tabular}{|c|c|c|c|c|c|c|c|}
\hline \multirow[b]{2}{*}{ Deviant } & \multicolumn{2}{|c|}{ Control group } & \multicolumn{2}{|c|}{ High-risk group } & \multicolumn{3}{|c|}{$T$-statistics } \\
\hline & $M$ & $S D$ & $M$ & $S D$ & $t$ & $d f$ & $p$ \\
\hline Standard & 487 & 153 & 529 & 140 & -1.32 & 86 & .188 \\
\hline Duration & 102 & 33 & 110 & 30 & -1.20 & 86 & .232 \\
\hline Frequency & 103 & 32 & 111 & 31 & -1.15 & 86 & .253 \\
\hline Vowel identity & 104 & 34 & 112 & 30 & -1.08 & 86 & .282 \\
\hline Duration control & 131 & 27 & 136 & 27 & -0.80 & 84 & .426 \\
\hline
\end{tabular}


Table 4

ERP Amplitudes of Both Groups (CO - Control Group, HR - High-risk Group) to the Standard Stimulus. Listed are Means (M, in Bold) in $\mu V$, Standard Deviations (SD) in $\mu V$, and One-sample t-statistics ( $\mathrm{t}$, df - Degrees of Freedom, p - Significance Level, Cohen's d - Effect Size) at the Channel Region of Interest (ROI; C - Central Channels) with the Maximal Amplitude in Selected Time Windows (TW; 1, 2). Statistical Significance is Marked with Asterisks ( $\left.{ }^{*} \mathrm{p}<.05,{ }^{* *} \mathrm{p}<.01,{ }^{* * *} \mathrm{p}<.001\right)$.

\begin{tabular}{|c|c|c|c|c|c|c|c|c|c|c|c|c|c|c|}
\hline \multirow{2}{*}{$\begin{array}{c}\text { TW } \\
\text { Group }\end{array}$} & \multicolumn{7}{|c|}{$1(233-333 \mathrm{~ms})$} & \multicolumn{7}{|c|}{2 (497-597 ms) } \\
\hline & $\mathrm{ROI}$ & $M$ & $S D$ & $t$ & $d f$ & $p$ & $d$ & $\mathrm{ROI}$ & $M$ & $S D$ & $t$ & $d f$ & $p$ & $d$ \\
\hline $\mathrm{CO}$ & $\mathrm{C}$ & 1.62 & 1.83 & 5.70 & 40 & $.000 * * *$ & 0.89 & $\mathrm{C}$ & -0.39 & 1.57 & -1.60 & 40 & .117 & -0.25 \\
\hline $\mathrm{HR}$ & C & 1.17 & 1.73 & 4.49 & 43 & $.000 * * *$ & 0.68 & C & -0.40 & 1.46 & -1.81 & 43 & .077 & -0.27 \\
\hline
\end{tabular}


Table 5

MMR Amplitudes of Both Groups (Control Group - CO, High-risk Group - HR) to the Deviant Types (DEV Deviant, DUR-Duration, DURC - Controlled Duration, FRE - Frequency, VOW-Vowel). Listed are Means (M, in Bold) in $\mu V$, Standard Deviations (SD) in $\mu V$, and Effect Sizes (Cohen's d) at the Channel Region of Interest (ROI; F - Frontal, C - Central, R-Right, L - Left Channels) with the Maximal Amplitude in Selected Time Windows (TW; I, II, III, IV). Statistical Significance is Marked with Asterisks (*p <.05, **p <.01, ***p<.001).

\begin{tabular}{|c|c|c|c|c|c|c|c|c|c|c|c|c|}
\hline \multirow{2}{*}{$\begin{array}{l}\text { DEV } \\
\text { Group }\end{array}$} & \multicolumn{4}{|c|}{ TW } & \multicolumn{4}{|c|}{ TW } & \multicolumn{4}{|c|}{ TW } \\
\hline & ROI & $M$ & $S D$ & $d$ & ROI & $M$ & $S D$ & $d$ & ROI & $M$ & $S D$ & $d$ \\
\hline DUR & \multicolumn{4}{|c|}{ I (290-340 ms) } & \multicolumn{4}{|c|}{ II (502-602 ms) } & \multicolumn{4}{|c|}{ III (677-777 ms) } \\
\hline $\mathrm{CO}$ & $\mathrm{F}$ & $*_{-0.75}$ & 1.82 & -0.41 & $\mathrm{~F}$ & $* * 2.12$ & 3.77 & 0.56 & $\mathrm{R}$ & $* * 1.69$ & 3.08 & 0.55 \\
\hline HR & $\mathrm{R}$ & -0.06 & 1.44 & 0.04 & $\mathrm{~F}$ & $* * * 2.34$ & 3.47 & 0.67 & $\mathrm{~F}$ & $* * * 2.65$ & 3.72 & 0.71 \\
\hline DURC & & & & & & & & & \multicolumn{4}{|c|}{ III (641-741 ms) } \\
\hline $\mathrm{CO}$ & & & & & & & & & $\mathrm{F}$ & $* * 1.99$ & 3.64 & 0.55 \\
\hline HR & & & & & & & & & $\mathrm{L}$ & $*_{1.41}$ & 3.38 & 0.42 \\
\hline FRE & \multicolumn{4}{|c|}{ I (252-302 ms) } & \multicolumn{4}{|c|}{ II (578-678 ms) } & \multicolumn{4}{|c|}{ III (740-840 ms) } \\
\hline $\mathrm{CO}$ & $\mathrm{F}$ & $* *-0.85$ & 1.48 & -0.57 & $\mathrm{~F}$ & 0.86 & 3.98 & 0.22 & $\mathrm{R}$ & 0.74 & 3.99 & 0.19 \\
\hline $\mathrm{HR}$ & C & -0.04 & 1.88 & -0.02 & $\mathrm{~L}$ & $* * 1.47$ & 2.87 & 0.51 & $\mathrm{~L}$ & $* * 1.27$ & 2.79 & 0.45 \\
\hline vow & \multicolumn{4}{|c|}{ I (422-522 ms) } & \multicolumn{4}{|c|}{ II (536-636 ms) } & \multicolumn{4}{|c|}{ III (715-765 ms) } \\
\hline $\mathrm{CO}$ & $\mathrm{F}$ & $* * * 1.50$ & 2.09 & 0.71 & $\mathrm{R}$ & $* * 1.43$ & 2.65 & 0.54 & $\mathrm{R}$ & $* * * 1.56$ & 2.72 & 0.57 \\
\hline HR & C & 0.70 & 2.37 & 0.30 & $\mathrm{~L}$ & 0.79 & 2.80 & 0.28 & $\mathrm{~L}$ & $* 0.96$ & 2.72 & 0.35 \\
\hline \multicolumn{5}{|c|}{ IV (790-840 ms) } & & & & & & & & \\
\hline $\mathrm{CO}$ & $\mathrm{R}$ & $* * 1.32$ & 2.87 & 0.46 & & & & & & & & \\
\hline HR & $\mathrm{L}$ & $* 1.14$ & 2.97 & 0.38 & & & & & & & & \\
\hline
\end{tabular}




\section{Figures}

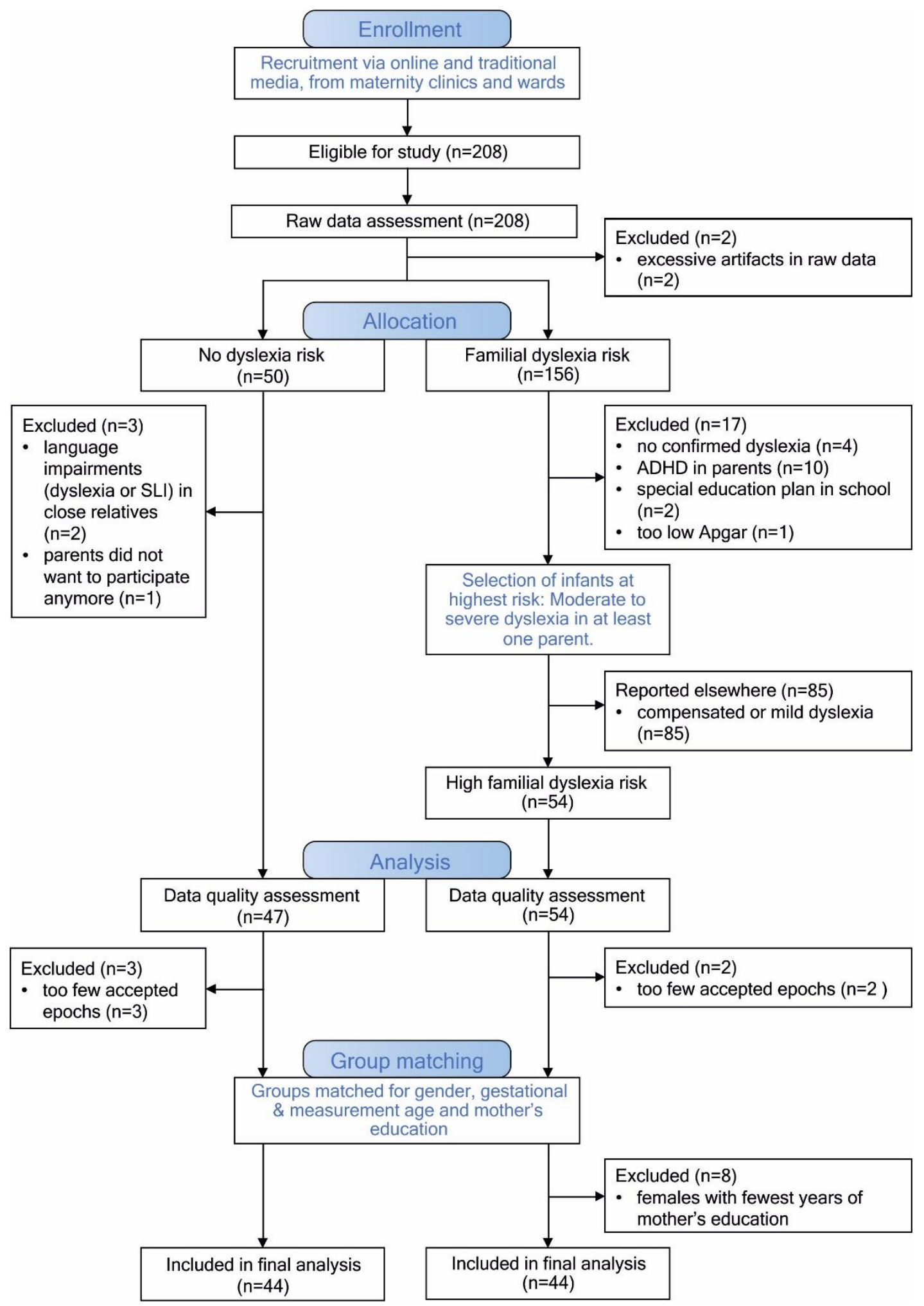

Figure 1. Flow chart illustrating participant recruitment and allocation to groups. 


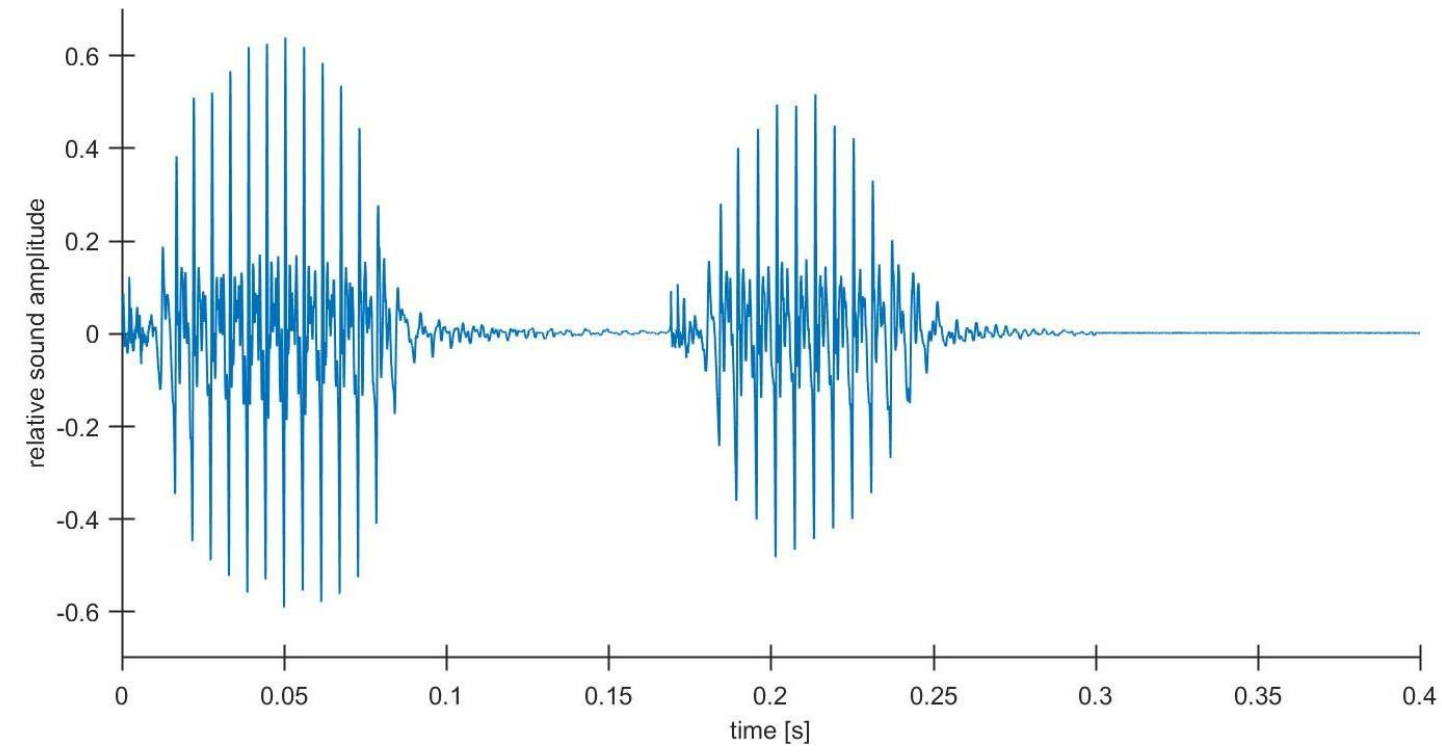

Figure 2. Waveform of /tata/ pseudoword. The sound amplitude is shown on a relative scale with the theoretical maximum of 1. 


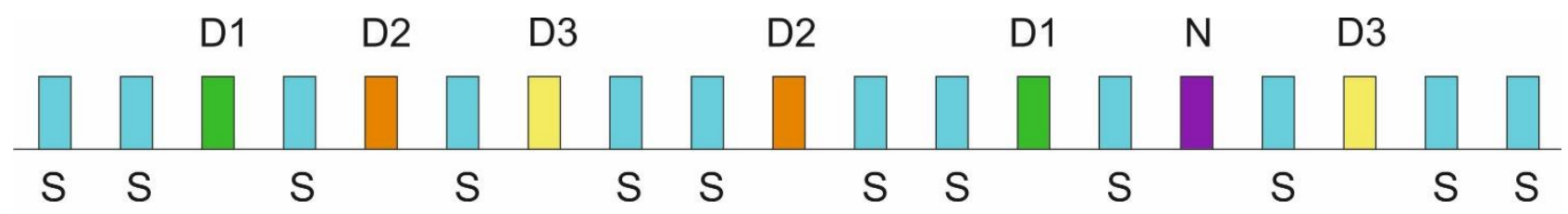

$\begin{array}{lll}\square & \text { standard S } & \text { /ta-ta/ } \\ \square & \text { frequency deviant D1 } & \text { /ta-ta/ } \\ \square & \text { vowel deviant D2 } & \text { /ta-to/ } \\ \square & \begin{array}{l}\text { duration deviant D3 } \\ \text { novel N }\end{array} & \text { /ta-ta:/ } \\ \square & \end{array}$

Figure 3. The stimulus paradigm used. The Finnish pseudoword/tata/ was presented as a frequent standard (S, blue) and its auditory deviations (frequency, vowel and duration deviants D1-D3, green, orange, yellow, respectively) as rare deviant stimuli. Novel auditory stimuli were presented very rarely. 


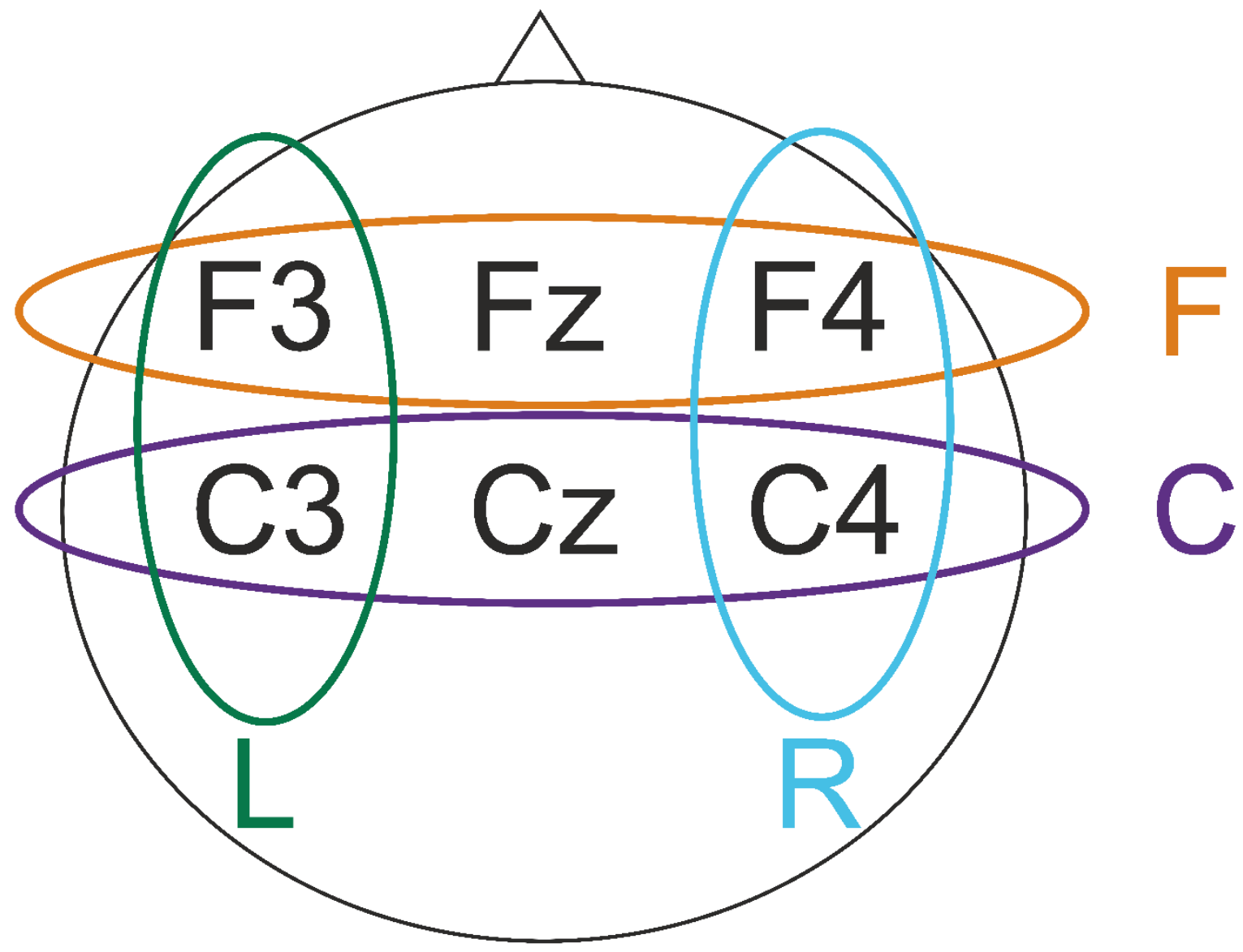

Figure 4. Formation of channel regions of interest (ROIs) from single EEG electrodes. 


\section{ERPs to standard stimulus}

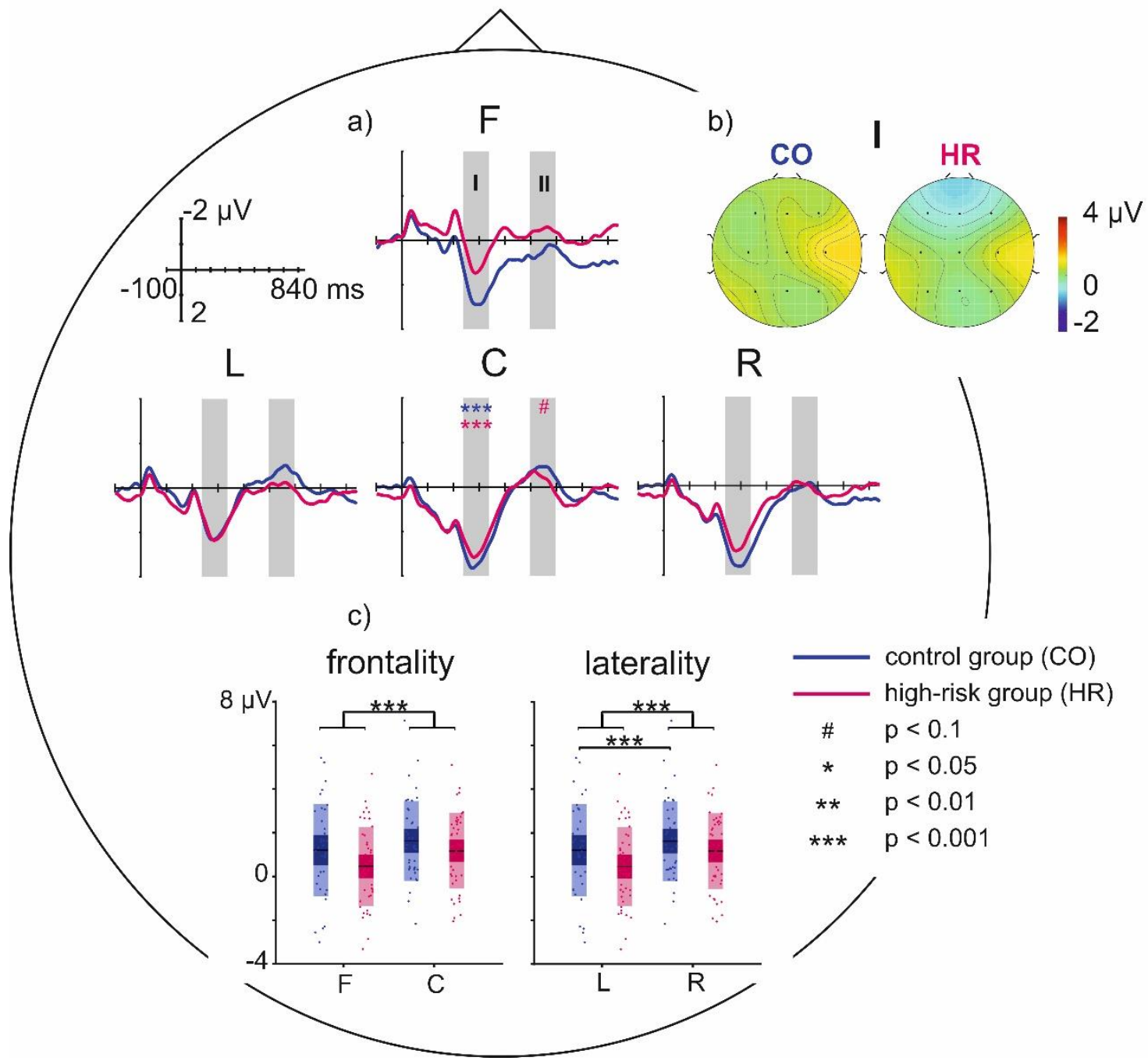

Figure 5. ERPs to standard stimulus /tata/ from the control group (CO, blue) and high-risk group (HR, pink).

a) Grand average ERPs in control and high-risk group at ROIs F, C, L, and R. Coloured asterisks and hashes indicate the level of significance of the standard response in the selected time window for the ROI with maximal amplitude for the respective group as verified by one-sample $t$-tests. b) Distribution of standard ERPs on the scalp for the early positivity (I). c) Frontality, laterality and group effects. Each individual data point reflects the average mean amplitude of one participant, dark horizontal bars are group means, dark shaded areas mark standard errors of group means, and light shaded areas mark standard deviations. Asterisks indicate the level of significance. 


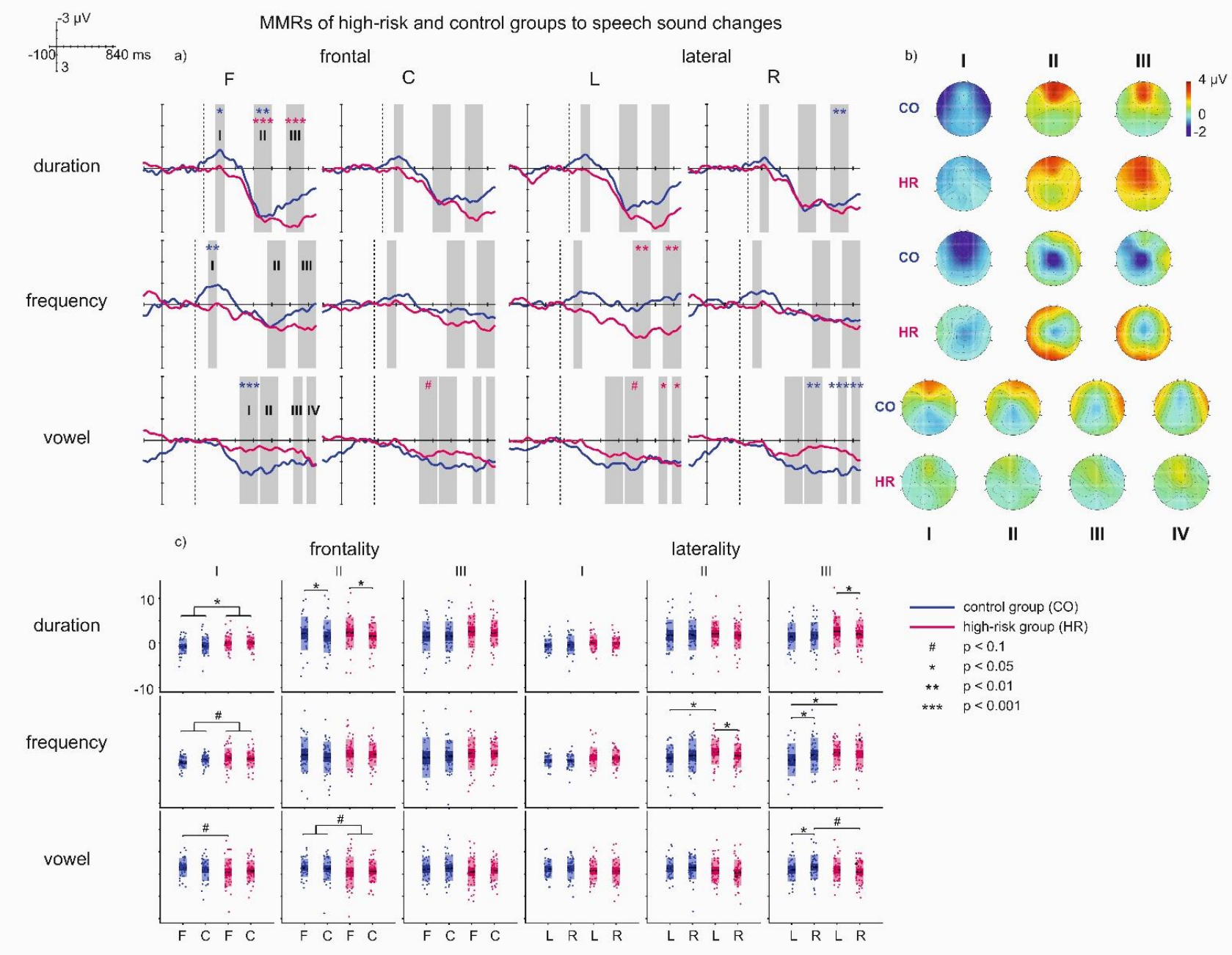

Figure 6. MMRs at F, C, L, and R ROIs of the high-risk (pink) and control groups (blue) to duration, frequency, and vowel identity changes. a) Difference curves. Change onset is marked by a vertical dotted bar preceded by a pre-stimulus baseline of $100 \mathrm{~ms}$. Latency windows are marked with a grey bar and roman numerals (referred to in the text). Asterisks and hashes depict MMRs' significances on the ROI with maximal amplitude as evaluated by one-sample $t$-tests. Groups are differentiated by colours. b) Distribution of MMRs on the scalp in the control group (CO) and high-risk (HR) group in all latency windows marked by roman numerals. c) Frontality, laterality, and group effects. Each individual data point represents the mean MMR amplitude of one participant, dark horizontal bars are group means, dark shaded areas mark standard errors of group means, and light shaded areas mark standard deviations. Asterisks and hashes indicate the level of statistical significance for group, hemispheric, or post-hoc comparisons of interaction effects (depicted by horizontal bars) resulting from ANOVA analysis. 


\section{MMRs to controlled duration stimulus}

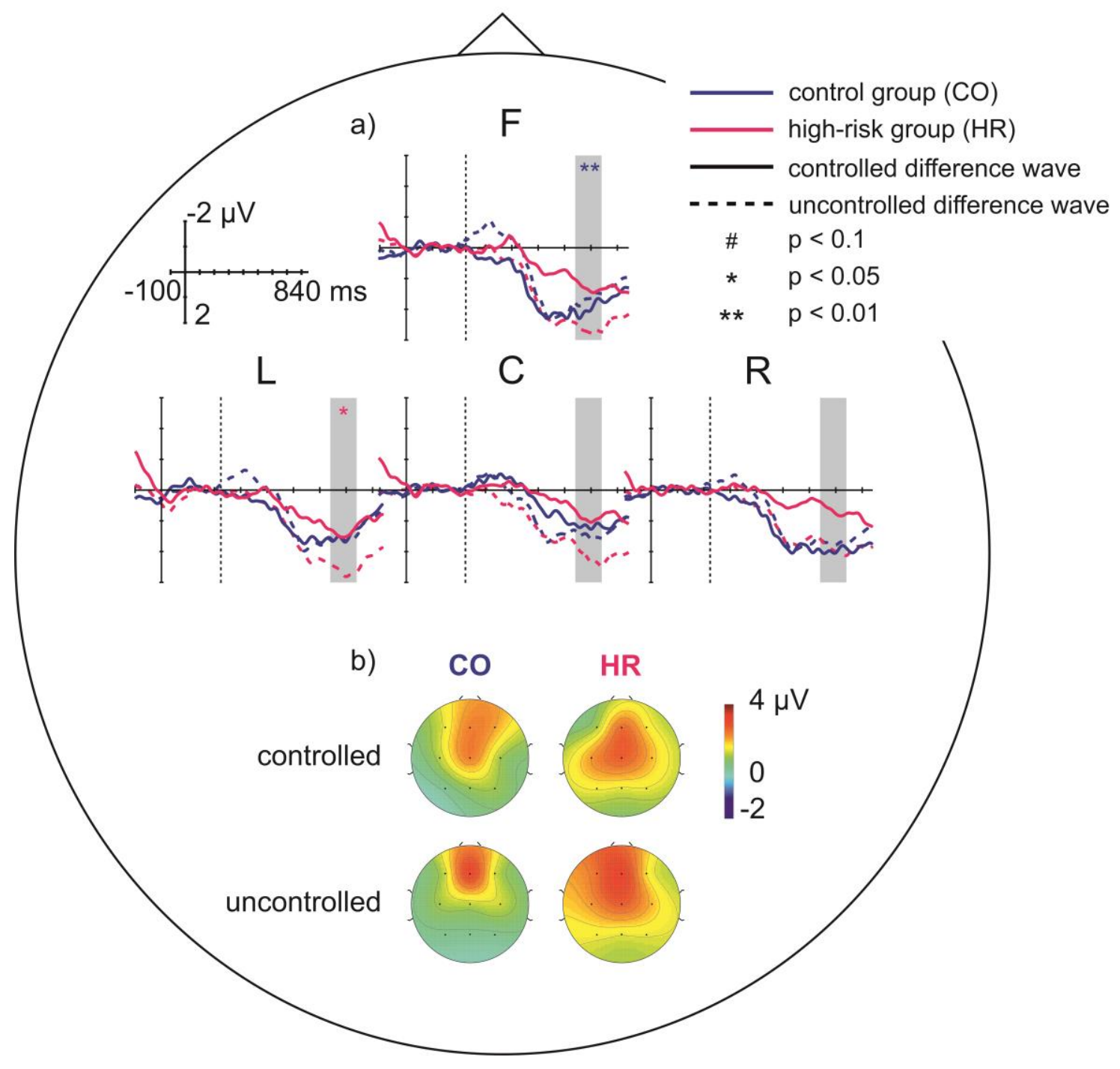

Figure 7. a) MMRs (difference waves) in the controlled duration condition (continuous line; duration deviant ERP was compared to the ERP to the same stimulus acting as a standard) compared to uncontrolled condition (dotted line). Change onset is marked by a vertical dotted bar preceded by a pre-stimulus baseline of $100 \mathrm{~ms}$ and the latency of interest is marked with a grey bar. Asterisks and hashes depict the controlled MMRs' significances as evaluated by one-sample $t$-tests. Groups are differentiated by colours. (b) Distribution of MMRs in controlled (641-741 ms) and uncontrolled (677-777 ms) conditions on the scalp for control group (CO) and high-risk (HR) group. 